\title{
Molecular characterization of enterococci harboring genotype and phenotype incongruence related to glycopeptide resistance isolated in Brazilian hospitals
}

\author{
Priscila Moraes Henrique, Izabel Cristina Vanzato Palazzo, Rosemeire Cobo Zanella', \\ Ana Lucia da Costa Darini/ ${ }^{+}$
}

Departamento de Análises Clínicas, Toxicológicas e Bromatológicas, Faculdade de Ciências Farmacêuticas de Ribeirão Preto, Universidade de São Paulo, Via do Café s/n, 14040-903 Ribeirão Preto, SP, Brasil 'Laboratório de Bacteriologia, Instituto Adolfo Lutz, São Paulo, Brasil

Three Enterococcus faecalis and one Enterococcus faecium strains were characterized by plasmid profile, pulsed-field gel electrophoresis (PFGE) and determination of antimicrobial minimal inhibitory concentrations. VanA elements were characterized by Long PCR, overlapping PCR and DNA sequencing. Enterococcal strains showed resistance to vancomycin and harbored the vanA gene, and three these were teicoplanin susceptible while one showed intermediate resistance to teicoplanin. Two E. faecalis strains showed indistinguishable PFGE profile while the third was unrelated. E. faecalis strains showed a deletion in the right terminal region of the Tn1546-like element. The E. faecium strain showed an insertion element in the vanXY intergenic region. Mutations in VanA elements were not found. Rearrangements in the VanA element could be responsible for incongruities in genotype and phenotype in these strains.

Key words: vancomycin resistant enterococcci (VRE) - vanA genotype - VanB phenotype

Control of nosocomial infections caused by vancomycin-resistant enterococci (VRE) has emerged as a worldwide health problem (Courvalin 2005, Vilela et al. 2006). Until the 1990s, most enterococcal infections could be successfully treated by a combination of vancomycin and aminoglycosides antibiotics. As VREs have become more prevalent, treatment options have been greatly reduced (Schouten et al. 2000).

VanA and VanB are widespread globally and confer the most prevalent glycopeptide resistance phenotype (Courvalin 2005). The VanA phenotype is characterized by inducible, high-level resistance to vancomycin and teicoplanin. VanB-resistant strains are also inducible and resistant to vancomycin, but retain susceptibility to teicoplanin. Resistance phenotypes have been associated with the acquisition of two gene clusters, van $A$ and $v a n B$. These gene clusters direct the synthesis of peptidoglycan precursors terminating with the depsipeptide D-alanylD-lactate, which bind glycopeptide with reduced affinity (Arthur et al. 1996).

The vanA gene cluster located on the Tn 1546 mobile genetic element is $10,851 \mathrm{bp}$ in size and encodes nine polypeptides that can be assigned to different functional groups. The products of vanA gene cluster include transposase and resolvase (ORF 1 and ORF 2), VanS and VanR proteins, which are a response regulator and histidine kinase sensor, respectively. VanH and VanA syn-

Financial support: FAPESP (05/50273-7)

+Corresponding author: aldarini@fcfrp.usp.br

Received 28 August 2007

Accepted 27 May 2008 thesize the depsipeptide D-alanyl-D-lactacte, VanX hydrolyses D-ala-D-ala, and VanY hydrolyzes the terminal $\mathrm{D}$-ala residue from the peptidoglycan precursor protein. Vancomycin or teicoplanin induce autophosphorylation of VanS, which in turn phosphorylates VanR. Phosphorylated VanR protein binds to the promoter region of van$H A X$ inducing transcription of genes encoding essential structural molecules (Arthur et al. 1992). The function of VanZ protein is unknown, but it has been related to teicoplanin resistance (Arthur et al. 1992, 1995).

Genetic heterogeneity in Tn1546-like element or VanA element has been documented (Hashimoto et al. 2000, Lee et al. 2004, Eom et al. 2004, Camargo et al. 2005). The polymorphisms described so far included mutations, insertion of insertions sequence (IS) and deletions.

In this study, the molecular characteristics of the Tn1546-like element in VanB phenotype-vanA genotype enterococccal strains isolated in Brazil are described in order to advance understanding of the resistance incongruities.

Bacterial strains - Two VRE strains studied, Enterococcus faecalis 28 and Enterococcus faecium 172 were isolated in 1998 during an outbreak (Casa de Saúde Santa Marcelina, São Paulo, Brazil). The other two strains included in this study, E. faecalis 211 and E. faecalis 217 were isolated in 2004 during a VRE surveillance program at the Hospital Paulistano (Zanella et al. 2006). The enterococcal strains that are described in this report were isolated from different patients.

Species identification and susceptibility profile The isolates were identified as Enterococcus spp. at the Instituto Adolfo Lutz (IAL), São Paulo, by conventional biochemical tests (Teixeira \& Facklam 2003). Minimal inhibitory concentrations (MIC) for vancomycin and 
teicoplanin were determined by agar dilution method according to the Clinical and Laboratory Standard Institute (CLSI 2005) and by Etest (AB BIODISK). The van $A$ and $v a n B$ genotype were determined by multiplex polymerase chain reaction (PCR) (Woodford et al. 1993). The strains were sent to the Laboratório Especial de Bacteriologia e Epidemiologia Molecular (LEBEM) at the Faculdade de Ciências Farmacêuticas of Ribeirão Preto - Universidade de São Paulo for confirmation of phenotype and genotype characterization. At LEBEM, the enterococcal species were confirmed using the protocol described by Dutka-Malen et al. (1995) followed by molecular characterization of the strains.

Pulsed-field gel electrophoresis (PFGE) profile-PFGE was performed after SmaI digestion of DNA (Campanile et al. 2003) in a Gene Navigator apparatus (Amersham, Uppsal, Sweden) at $180 \mathrm{~V}$ for $25 \mathrm{~h}$ at $7^{\circ} \mathrm{C}$ with pulses of $20 \mathrm{~s}$ for $10 \mathrm{~h}, 8 \mathrm{~s}$ for $10 \mathrm{~h}$ and $3 \mathrm{~s}$ for $5 \mathrm{~h}$. The DNA restriction patterns were interpreted as previously described (Tenover et al. 1995).

Plasmid profile - Enterococci plasmid DNAs were extracted by the alkaline lysis method (Birnboim \& Doly 1979$)$ and analyzed by electrophoresis on $1 \%$ agarose gels. Plasmid size was determined by comparison to plasmid standards from Escherichia coli V517 (NCTC 50193) and E. coli 39R861 (NCTC 50192) strains.

Location of VanA element - Southern blot hybridization analysis was performed using digoxigenin-labeled DNA probes following procedures described in the DIG System User Guide for filter hybridization (Boehringer, Mannheim, Germany). Southern blot hybridization was performed to determine molecular locations of the VanA element. Briefly, plasmid DNA was blotted onto nylon membranes (Hybond $\mathrm{N}+$, Amersham) and hybridized with digoxigenin-labeled vanA probe (Woodford et al. 1993). Also, genomic DNA digested with I-CeuI followed by PFGE was Southern blotted onto nylon membranes, and the blots were hybridized with digoxigenin- labeled vanA and 16S rRNA gene probes (Palazzo et al. 2006).

Characterization of Tn1546-like elements - The characterization of $\mathrm{Tn} 1546$ - like elements was performed by Long PCR using the Expand Long Template PCR system (Boehringer, Mannheim, Germany) with a single prime target, the inverted repeat sequence of $\operatorname{Tn} 1546$ (Woodford et al. 1997). VanA elements in enterococci strains were characterized by overlapping PCR using ten pairs of PCR primers (Woodford \& Stigter 1998). The PCR products of VanA resistance element were purified using a GFX kit and were sequenced using the MegaBace ${ }^{\mathrm{TM}}$ apparatus (Amersham Biosciences, Australia). E. faecium BM 4147, which carries a prototype of $\operatorname{Tn} 1546$, was used as a control.

Determination of promoter - The van $X Y$ intergenic region was amplified by PCR, using E. faecium 4147 DNA as the template. It was cloned into a pKK232-8 vector (Amersham Biosciences, Australia) containing the promoterless choramphenicol acetyltransferase (cat) gene. The amplification primers were Pzl GGATCCGCTATTTTGATTTCCCCGTT and Pz2 GTCGACCCTAAGTATATTAAGAATAAC, which contained cut sites for the restriction enzymes SalI and BamHI (underlined above). Restriction enzyme digestion is used to insure DNA fragment correct orientation upstream to the cat gene. The PCR product and pKK 232-8 were both digested with SalI and BamHI enzymes and were ligated using T4 DNA ligase. The cloned product was transfected by electroporation into $E$. coli $\mathrm{DH} 10 \mathrm{~B}$, which was cultured in Luria Bertani (LB) broth for $1 \mathrm{~h}$ at $37^{\circ} \mathrm{C}$ with gentle agitation. Subsequently, the cells were spread on LB agar plates supplemented with $10 \mu \mathrm{g} / \mathrm{ml}$ of cloramphenicol. Expression of the cat gene was used to demonstrate presence of promoter.

Species identification and characterization of resistance profile - Three isolates identified by multiplex PCR as E. faecalis 28, 211 and 217 showed high resistance to vancomycin and susceptibility to teicoplanin which establishes the VanB phenotype. The other isolate, identified as E. faecium 172 showed resistance to vancomycin and intermediate resistance to teicoplanin. Vancomycin and teicoplanin MICs for isolates are shown in Table. The multiplex PCR assay indicated the presence of a $399 \mathrm{bp}$ product corresponding to the vanA gene in all enterococci studied.

Analysis of clonality, plasmid profile and location of VanA element - E. faecalis 211 and 217, isolated during the 2004 surveillance showed indistinguishable PFGE profiles after SmaI digestion, indicating a single clone. $E$. faecalis 28 isolated in 1998 was genetically unrelated to these (Fig. 1). All strains showed the same plasmid $70 \mathrm{~Kb}$ plasmid (Fig. 2A). Southern blot hybridization with a vanA probe demonstrated presence of the vanA plasmid in E. faecium 172. The vanA probe hybridization with both fragments corresponding to chromosomal and plasmid DNA were shown by E. faecalis 211, E. faecalis 217 and E. faecalis 28 (Fig. 2B) but different results were obtained in subsequent assays. No co-hybridization of the 16SrRNA and vanA probes after $I-C e u$ I digestion of chromosomal DNA followed by PFGE indicated that those strains do not carry a copy of the vanA gene in their chromosomal DNA.

Molecular characterization of Tn1546-like elements - Characterization of Tn1546-like elements of the four VRE strains by Long PCR and overlapping PCR are summarized in Table. Three E. faecalis strains showed deletion of vanYZ genes and the right terminal repeat. $E$. faecium 172 showed insertion of an IS element, ISEfa5, between the van $X$ and $\operatorname{van} Y$ genes, located immediately after nucleotide 9,013 of Tn 1546 and flanked by 8 bp direct repeats, as previously reported by Camargo et al. (2005). According to the results obtained in this study, no promoter was detected between the $\operatorname{van} X$ and $\operatorname{van} Y$ genes. DNA sequencing indicated the strains had no mutations in vanS gene.

The VREs in this study were isolated in hospitals located in the city of São Paulo, Brazil, and showed incongruities in genotype and phenotype such as the VanB phenotype and the vanA genotype (Palazzo et al. 2006, Zanella et al. 2006). The same incongruities have been described in studies conducted in Korea, Japan and 


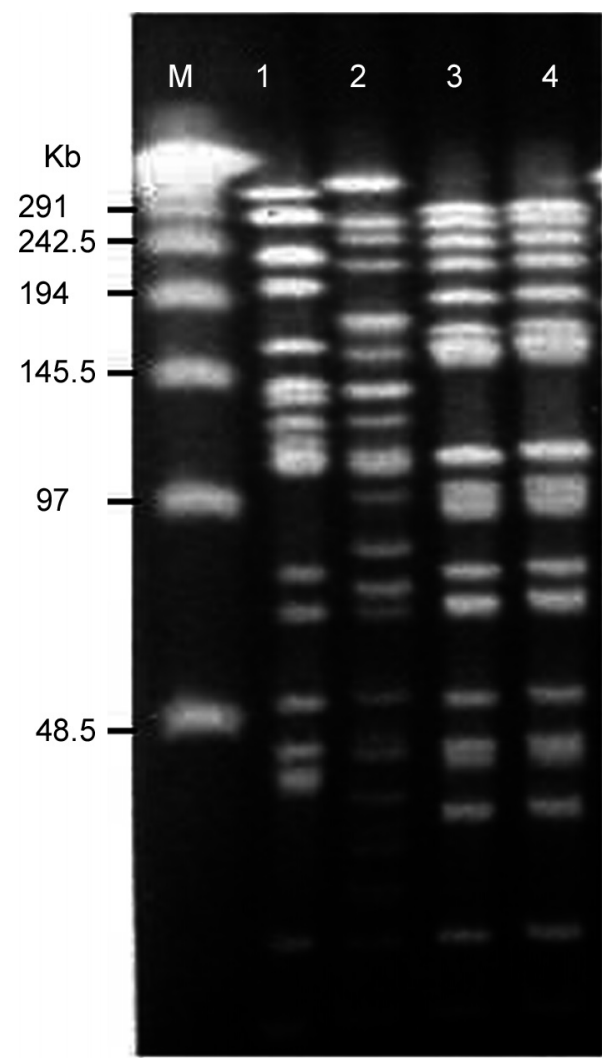

Fig. 1: pulsed-field gel electrophoresis (PFGE) patterns after SmaI digestion of total DNA extracted from the vancomycin resistant Enterococcus faecalis strains. Lanes - M: molecular size weight (Lambda Ladder PFG Marker, New England Biolabs); 1-4: E. faecalis vanA (control strain), E. faecalis 28, E. faecalis 211, E. faecalis 217, respectively.
Taiwan. This suggests that point mutations in the vanS regulatory gene or impairment of VanY and VanZ accessory proteins may serve as mechanism for loss of teicoplanin resistance (Hashimoto et al. 2000, Lauderdale et al. 2002, Lee et al. 2004, Ko et al. 2005, Tanimoto et al. 2005, Song et al. 2006). Although E. faecalis 28, E. faecalis 211 and E. faecalis 217 presented VanB phenotype-vanA genotype, no mutation was found in the van $S$ gene (Hashimoto et al. 2000).

The mechanism for VanZ protein associated teicoplanin resistance is unknown. Several authors (Arthur et al. 1994, Gold 2001, Courvalin 2006) reported that vanRSHAX genes promote cell wall alterations compatible with resistance to glycopeptides. These authors stated that the VanZ protein does not contribute to produce the pentadepsipeptide, the peptidoglycan precursor terminating in D-ala-D-lac, which is present in VRE strains (Arthur et al. 1995). Teicoplanin susceptibility in the strains in this study could be caused by genetic rearrangements in the right portion of Tn1546-like elements characterized by deletion of the vanY and vanZ genes which encode proteins important for the resistance mechanism in some situations. Thus, the denomination "accessory proteins" used in a majority of reports for products of vanY and $v a n Z$ genes are inadequate.

Interestingly, E. faecium 172 contained an insertion of ISEfa 5 in the intergenic region of vanXY genes, which could be the cause of the low-level resistance to teicoplanin. Other authors (Lee et al. 2004, Shin et al. 2006) have reported the presence of IS1216V in enterococci strains with the same phenotypic characteristics related to teicoplanin. The ISEfa5 insertion could interrupt a promoter preventing activation of $\operatorname{van} Y$ and $\operatorname{van} Z$ genes
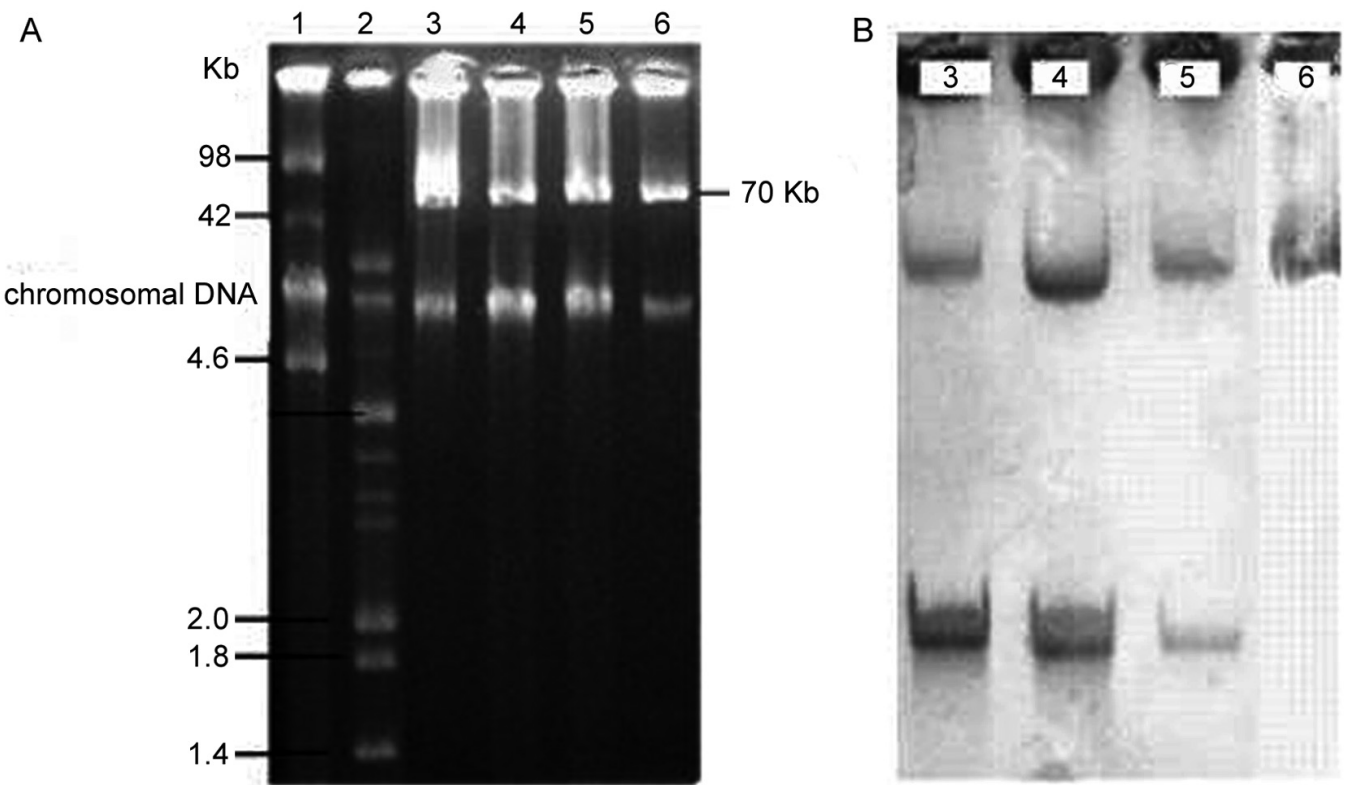

Fig. 2: agarose gel electrophoresis showing plasmid profiles and hybridization with the $v a n A$ probe. A: plasmid profiles of vancomycin resistant enterococcci (VRE) isolates after alkaline lyses extraction and agarose gel electrophoresis. Lines - 1-6: Escherichia coli 39R861; E. coli V517; E. faecalis 28; E. faecalis 211; E. faecalis 217; E. faecium 172, respectively; B: Southern blot corresponding to panel A and hybridization with vanA probe. Lines - 3-6: E. faecalis 28; E. faecalis 211; E. faecalis 217; E. faecium 172, respectively. 
TABLE

Determination of minimal inhibitory concentrations (MIC) to glycopeptides and characterization of VanA elements by overlapping polymerase chain reaction (PCR)

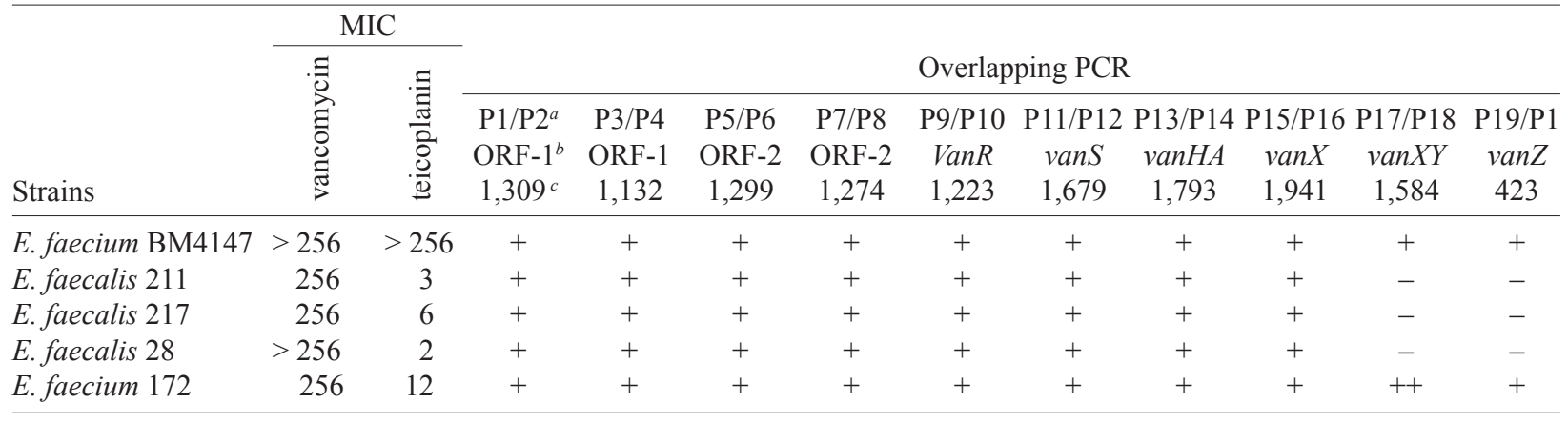

$a$ : primers (Woodford et al 1998); $b$ : genes amplified by PCR; $c$ : size of amplified fragments in base pairs; $(+)$ : fragment is indistinguishable from prototype $\mathrm{Tn} 1546 ;(++)$ : fragment longer than prototype; (-): no fragment.

by phosphorylated VanR protein as occur in vanH promoter. Arguing against this is the fact that cloning analyses do not indicate the presence of a promoter between vanX and vanY genes. Another possibility is deletion of genes after the ISEfa5 insertion. Refuting this is the fact that sequencing of the VanA element indicates that the vanX and vanY genes are intact. A more plausible explanation would be that the ISEfa5 insertion hinders activation of the transcription of vanY and vanZ genes by promoter $\mathrm{H}$.

Molecular characterization of Tn1546-like elements is important to better understand VRE epidemiology. E. faecalis 28 isolated in Hospital Santa Marcelina in 1998 shows the same Tn1546-like element and plasmid profile as strains E. faecalis 211 and E. faecalis 217 which were isolated much later, in 2004 in a different hospital (Hospital Paulistano).

In conclusion, the endemic nature of VRE occurrence is a serious medical problem. Exchange of genetic material among enterococcal strains is very likely and exacerbates the problem. Structural integrity of the VanA element and the presence of vanY and vanZ genes are important to maintain the glycopeptide resistant phenotype.

\section{REFERENCES}

Arthur M, Depardieu F, Molinas C, Reynolds P, Courvalin P 1995. The vanZ gene of Tn1546 from Enterococcus faecium BM 4147 confers resistance to teicoplanin. Gene 154: 87-92.

Arthur M, Depardieu F, Reynolds P, Courvalin P 1996. Quantitative analysis of the metabolism of soluble cytoplasmic peptidoglycan precursors of glycopeptide-resistant enterococci. Mol Microbiol 21: 33-44.

Arthur M, Depardieu F, Snaith H, Reynolds P, Courvalin P 1994. Contribution of VanY D, D- carboxypeptidase to glycopeptides resistance in Enterococcus faecalis by hydrolyses of peptidoglycan precursors. Antimicrob Agents Chemother 38: 1899-1903.

Arthur M, Molinas C, Courvalin P 1992. The VanS-VanR two component regulatory system controls synthesis of depsipeptide peptidoglycan precursors in Enterococcus faecium BM4147. J Bacteriol 174: 2582-2591.

Birnboim HC, Doly J 1979. A rapid alkaline extraction procedure for screening recombinant plasmid DNA. Nucleic Acids Res 7: $1513-1523$.
Camargo IL, Zanella RC, Brandileno MC, Pignatari AC, Goldman GH, Woodford N, Darini AL 2005. Occurrence of insertion sequences within the genomes and $\mathrm{Tn} 1546$-like elements of glycopeptide-resistant enterococci isolated in Brazil, and identification of a novel element, ISEfa5. Int J Med Microbiol 294: 513-519.

Campanile F, Bartoloni A, Bartalesi F, Bartalesi F, Borbone S, Mangani V, Mantella A, Nicoletti G, Paradisi F, Russo G, Strohmeyer M, Stefani S 2003. Molecular alterations of VanA element in vancomycin-resistant enterococci isolated during a survey of colonized patients in an Italian intensive care unit. Microb Drug Resist 9: 191-199.

CLSI - Clinical and Laboratory Standards Institute 2005. Approved standard M7-A6. Methods for dilution antimicrobial susceptibility tests for bacteria that grow aerobically, Pennsylvania, $49 \mathrm{p}$.

Courvalin P 2005. Genetics of glycopeptide resistance in gram-positive pathogens. Int J Med Microbiol 294: 479-486.

Courvalin P 2006. Vancomycin resistance in Gram-positive cocci. Clin Infect Dis 42: 25-34.

Dutka-Malen S, Evers S, Courvalin P 1995. Detection of glycopeptide resistance genotype and identification to the species level of clinically relevant enterococci by PCR. J Clin Microbiol 33: 24-27.

Eom JS, Hwang I, Hwang B, Lee J, Cheong H, Park Y, Park S, Kim W 2004. Emergence of vanA genotype vancomycin-resistant enterococci with low or moderate levels of teicoplanin resistance in Korea. J Clin Microbiol 42: 1785-1786.

Gold HS 2001. Vancomycin-resistant enterococci: mechanisms and clinical observations. Clin Infect Dis 33: 210-219.

Hashimoto Y, Tanimoto K, Ozawa Y, Murata T, Ike Y 2000. Amino acid substitutions in the VanS sensor of the VanA-type vancomycin-resistant enterococcus strains result in high-level vancomycin resistance and low-level teicoplanin resistance. FEMS Microbiol Lett 185: 147-154.

Ko KS, Baek JY, Lee JY, Oh WS, Peck KR, Lee NY, Lee WG, Lee K, Song JH 2005. Molecular characterization of vancomycin resistant Enterococcus faecium isolates from Korea. J Clin Microbiol 43: $2303-2306$

Lauderdale TL, McDonald LC, Shiau YR, Chen PC, Wang H, Lai FJ, Ho M 2002. Vancomycin-resistant enterococci from humans and retail chickens in Taiwan with unique VanB phenotype-vanA genotype incongruence. Antimicrob Agents Chemother 46: 525-527.

Lee WG, Huh JY, Cho SR, Lim YA 2004. Reduction in glycopeptide resistance in vancomycin-resistant enterococci as a result of 
vanA cluster rearrangements. Antimicrob Agents Chemother 48: 1379-1381.

Palazzo IC, Camargo IL, Zanella RC, Darini AL 2006. Evaluation of clonality in enterococci isolated in Brazil carrying Tn1546-like elements associated with vanA plasmids. FEMS Microbiol Lett 258: 29-36.

Schouten MA, Hoogkamp-Korstanje JAA, Meis JFG, Voss A, European VRE study group 2000. Prevalence of vancomycin-resistant enterococci in Europe. Eur J Clin Microbiol Infect Dis 19: 816-822.

Shin E, Hong H, Ike Y, Lee K, Park YH, Cho DT, Lee Y 2006. VanBvanA incongruent VRE isolated from animals and humans in 1999. J Microbiol 44: 453-456.

Song JH, Ko KS, Oh WS, Park S, Heo ST, Kwon KT, Ryu SY, Peck KR, Lee NY 2006. High frequency of vancomycin-resistant Enterococcus faecium isolates with VanB phenotype and vanA genotype in Korean hospitals. Diagn Microbiol Infect Dis 56: 401-407.

Tanimoto K, Nomura T, Hamatani H, Xiao YH, Ike YA 2005. Vancomycin-dependent VanA-type Enterococcus faecalis strain isolated in Japan from chicken imported from China. Lett Appl Microbiol 41: 157-162.

Teixeira LM, Facklam RR 2003. Enterococcus. In PR Murray, EJ Baron, JH Jorgensen, MA Pfaller, RH Yolken (eds), Manual of Clinical Microbiology, 8th ed., American Society for Microbiology, Washington, DC, pp. 422-433.
Tenover FC, Arbeit RD, Goering RV, Mickelsen PA, Murray BE, Persing DH, Swaminathan B 1995. Interpreting chromosomal DNA restriction patterns produced by pulsed-field gel electrophoresis: criteria for bacterial strain typing. J Clin Microbiol 33: 2233-2239.

Woodford N, Morrison D, Johnson AP, Briant V, George RC, Cookson B 1993. Application of DNA probes for rRNA and vanA genes to investigation of a nosocomial cluster of vancomycin-resistant enterococci. J Clin Microbiol 31: 653-658.

Woodford N, Stigter L 1998. Molecular investigation of glycopeptide resistance in Gram-positive bacteria. In N Woodford, AP Johnson, Molecular bacteriology: protocols and clinical applications, Humana Press, New Jersey, p. 579-615.

Woodford N, Watson AP, Chadwick PR 1997. Investigation by long PCR of genetic elements mediating VanA glycopeptide resistance in enterococci from uncooked meat in South Manchester. Adv Exp Med Biol 418: 409-412.

Vilela MA, Souza SL, Palazzo IC, Ferreira JC, Morais MA Jr, Darini AL, Morais MM 2006. Identification and molecular characterization of Van A-type vancomycin-resistant Enterococcus faecalis in Northeast of Brazil. Mem Inst Oswaldo Cruz 101: 715-719.

Zanella RC, Lima MJC, Tegani LS, Hitomi A, Brandileone AC, Palazzo IC, Darini ALC 2006. Emergence of vanB phenotypevanA genotype in vancomycin-resistant enterococci in Brazilian hospital. Braz J Microbiol 37: 117-118. 